\title{
Drug Resistance of Enteric Bacteria
}

\section{Introduction of Bacteriophage P1CM into Salmonella typhi and Formation of PldCM and F-CM Elements}

\author{
EIKO KONDO AND SUSUMU MITSUHASHI \\ Department of Microbiology, School of Medicine, Gunma University, Maebashi, Japan
}

Received for publication 24 January 1966

\begin{abstract}
KoNDo, EIKo (Gunma University, Maebashi, Japan), AND Susumu MitsuHASHI. Drug resistance of enteric bacteria. VI. Introduction of bacteriophage P1CM into Salmonella typhi and formation of P1dCM and F-CM elements. J. Bacteriol. 91: 1787-1794. 1966.-Bacteriophage P1CM was introduced into Salmonella typhi by means of both phage infection and conjugation with Escherichia coli $\mathrm{F}^{+}$lysogenic for the phage. Upon incubation with a P1CM phage lysate, $S$. typhi and $S$. abony yield $C M^{\mathrm{r}}$ cells which are lysogenic for P1CM, but $S$. typhimurium LT2 does not. The P1CM phage is adsorbed slightly to $S$. typhi, but no infectious centers are formed when the phage is plated on this strain. Tests on P1CM-adsorbing capacity of the $S$. typhi $\mathrm{P} \mathrm{CM}^{+}$strain and on plaque formation and transduction ability of the recovered phage from this strain indicated that the cell and the phage population did not have any special advantage over the original cell and phage population. Conjugation of $S$. typhi with $E$. coli $\mathrm{F}^{+}$carrying $\mathrm{P} C^{+} M^{+}$gave three types of $S$. typhi $C M^{\mathrm{r}}$ clones: those which carry the whole P1CM phage, those with the P1dCM element, and those with nontransferable $C M^{\mathrm{r}}$. The second type has the $\mathrm{F}$ factor and is sensitive to f phages in spite of its typical behavior, serologically and biochemically, as $S$. typhi. It can donate the $\mathrm{P} 1 d C M$ and $\mathrm{F}^{+}$characters to $E$. coli $\mathrm{F}^{-}$or $\mathrm{F}^{-} / \mathrm{P} 1$ strains. As a consequence of conjugation with the $E$. coli $\mathrm{F}^{+}$strain, the $C M^{\mathrm{r}}$ character of the third type of $S$. typhi, the nontransferable $C M^{\mathrm{r}}$ element, acquired conjugational transferability, owing to the formation of the element, F-CM. This element can be transferred to an $E$. coli $\mathrm{F}^{-}$strain at a very high frequency (ca. $10^{\circ}$ ). Both the $\mathrm{F}$ and $C M^{\mathrm{r}}$ determinants are jointly transduced with $\mathrm{P} 1$ phage and are jointly eliminated by acridine dye treatment.
\end{abstract}

In a previous paper (16), bacteriophage P1CM was reported to carry all the pertinent phage activities of $\mathrm{P} 1$, as well as the $C M^{\mathrm{r}}$ character. P1CM multiplies by lytic growth, forming plaques similar to that of normal P1. Transduction of $C M^{\mathrm{r}}$ to recipient cells occurs following lysogenization.

It is known that phage P1 grows on Shigella (dysenteriae) and Escherichia coli (B, C, and $\mathrm{K}$ ) strains (5). Since Salmonella typhi was thought to be unaffected by P1 or P1CM infection, it was used as a recipient for testing transfer by conjugation of the $C M^{\mathrm{r}}$ portion of P1CM. S. typhi $C M^{\mathbf{r}}$ clones were obtained, however, as a result of mixed incubation, not only with the P1CMcarrying strain, but also with the cell-free lysate of P1CM.

This paper deals with the introduction of P1CM into $S$. typhi by phage infection and through conjugation with $E$. coli carrying the $F$ factor and P1CM prophage. Whereas infection of $S$. typhi by P1CM produced only $S$. typhi lysogenic for $\mathrm{P} 1 C M$, conjugation with $E$. coli $\mathrm{F}^{+} \mathrm{P} 1 C M^{+}$ resulted in $S$. typhi clones carrying various $\mathrm{P} 1 C M$ derivatives which were different in P1 function, i.e., complete $\mathrm{P} 1 C M$, defective $\mathrm{P} 1 C M$, or only the $C M^{\mathrm{r}}$ portion.

\section{Materials AND Methods}

Microorganisms. Bacterial strains used are listed in Table 1. S. dysenteriae $\mathrm{Sh} / \mathrm{s}$ was used as the indicator strain for phage P1CM as well as phage P1. S. typhi H901 and S. abony 74 are standard strains of Salmonella. Resistant strains (P1) were prepared as needed.

Bacteriophages used were P1CM, f1 [isolated by Loeb (18)], and f2 [isolated by Loeb and Zinder (19)]. Phage lysates were prepared by the agar layer method (31) and sterilized with chloroform. P1CM 
TABLE 1. Bacterial strains used

\begin{tabular}{|c|c|}
\hline Strain & Relevant characters \\
\hline \multicolumn{2}{|l|}{ Shigella } \\
\hline $\begin{array}{r}\text { S. dysenteriae } \\
\text { Sh/s....... }\end{array}$ & $S M^{\mathrm{r}}$ \\
\hline \multicolumn{2}{|l|}{ Salmonella } \\
\hline $\begin{array}{l}\text { S. abony } 74 \ldots \\
\text { S. typhimurium }\end{array}$ & $l a c^{-}$ \\
\hline LT2 ........ & $l a c^{-}$ \\
\hline S. typhi $\mathrm{H} 901$. & $\mathrm{lac}^{-}$ \\
\hline St-1 and St-22. & $\begin{array}{l}\mathrm{F}^{+}, \mathrm{P} 1 \mathrm{dCM}^{+}, \mathrm{lac}^{-} \text {(by cross of } \\
\text { S. typhi H } 901 \text { with } E \text {. coli } \\
\text { Tr 30-5) }\end{array}$ \\
\hline St-3. & $\begin{array}{c}\text { lac }^{-}, C M^{\mathrm{r}} \text { (by cross of } S . \text { typhi } \\
\text { H } 901 \text { with } E \text {. coli } \operatorname{Tr} 30-5)\end{array}$ \\
\hline ML 1154 . & $\begin{array}{l}\mathrm{F}^{-}, \text {lac }^{-}, \mathrm{P}^{\prime} \mathrm{CM}^{+} \text {(by transduc- } \\
\text { ing } S . \text { typhi H } 901 \text { with } \\
\quad \mathrm{P} 1 C M)\end{array}$ \\
\hline \multicolumn{2}{|l|}{ Escherichia coli } \\
\hline $\mathrm{K}-12 \mathrm{~F}^{+}$wild. . & $\mathrm{F}^{+}$, prototroph \\
\hline $\mathrm{K}-12 \mathrm{~F}^{-}$wild. & $\begin{array}{l}\mathrm{F}^{-} \text {, prototroph (by elimina- } \\
\text { tion of } \mathrm{F} \text { with acridine or- } \\
\text { ange treatment of } \mathrm{F}^{+} \text {wild } \\
\text { strain) }\end{array}$ \\
\hline K-12 W3110. & $\mathrm{F}^{\sim}, L p^{-}$ \\
\hline K-12 W1895. & $\mathrm{Hfr}, \mathrm{met}^{-}$ \\
\hline K-12 W3630. & ${ }_{3}, \mathrm{mal}^{-}$ \\
\hline K-12 W4574 & $\begin{array}{l}\mathrm{F}^{-}, \mathrm{pro}^{-}, \mathrm{lac}^{-}, \mathrm{ara}^{-}, \mathrm{mtl}^{-}, x y l^{-} \text {, } \\
\text { mal- } \mathrm{gal}^{-}, \mathrm{SM}^{\mathrm{r}}\end{array}$ \\
\hline K-12 W2984 . . & $\mathrm{F}^{-}, \mathrm{pro}^{-}$ \\
\hline $\mathrm{K}-1258-161 \mathrm{~F}^{-}$ & $\mathrm{F}^{-}$, met $^{-}$ \\
\hline K-12 PA200 . & 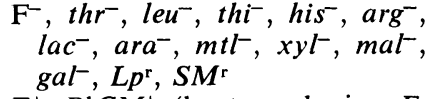 \\
\hline $\operatorname{Tr} 30-5$. & $\begin{array}{c}\mathrm{F}^{+}, \mathrm{PlCM}^{+} \text {(by transducing } E \\
\left.\text { coli } \mathrm{K}-12 \mathrm{~F}^{+} \text {with } \mathrm{PlCM}\right)\end{array}$ \\
\hline $\operatorname{Tr} 62-3 \ldots$ & $\begin{array}{l}\mathrm{F}^{-}, L p^{-}, \mathrm{PlCM}^{+} \text {(by transduc- } \\
\text { ing } E \text {. coli } \mathrm{K}-12 \mathrm{~W} 3110 \text { with } \\
\mathrm{PICM} \text { propagated on the } \\
\text { strain) }\end{array}$ \\
\hline K57. & $\begin{array}{l}(\mathrm{F}-C M)^{+}, \text {prototroph } \quad \text { by } \\
\text { cross of } E \text {. coli } \mathrm{K}-12 \mathrm{~F}^{+} \text {wild } \\
\text { type with } \mathrm{St}-3)\end{array}$ \\
\hline
\end{tabular}

lysates were usually prepared by using P1CM phage $\left(10^{6}\right.$ to $10^{7}$ per milliliter) obtained by ultraviolet (UV) induction of $E$. coli $\operatorname{Tr} 62-3\left(\mathrm{~F}^{-} \mathrm{P} 1 C^{+}\right.$; 16), with $E$. coli $\mathrm{K}-12 \mathrm{~W} 3110$ as the propagating strain.

The following notations are used: lac, lactose; ara, arabinose; $m t l$, mannitol; $x y l$, xylose; $m a l$, maltose; gal, galactose; met, methionine; pro, proline; $t h r$, threonine; leu, leucine; thi, thiamine; his, histidine; arg, arginine; $L p$, chromosomal locus of prophage $\lambda ; \mathbf{C M}$, chloramphenicol; TC, tetracycline; SM, streptomycin; + , fermenting a sugar, not requiring a nutrient or carrying a genetic element; -, nonfermenting, requiring, or not carrying a genetic element; $r$, resistant; $s$, sensitive; $i$, immune.
Media and stock solutions of drugs were prepared according to methods reported previously (16).

Assay of phage and bacteria, and the transduction procedures were the same as described in a previous paper (16). All incubations were done at $37 \mathrm{C}$.

P1 lysogeny test. A loopful of L-broth culture was spotted onto L-broth agar containing SM $(200 \mu \mathrm{g} / \mathrm{ml})$, seeded previously with $S$. dysenteriae $\mathrm{Sh} / \mathrm{s}$ (6). Strains lysogenic for P1 or P1CM give a similar positive response in this test.

Pl immunity test. P1 lysates (ca. $10^{8}$ phage per milliliter) were spotted onto a bacterial lawn streaked on eosin-methylene blue (EMB) complete agar without sugar. Strains which did not give lysis with P1, but were lysed by virulent $P 1$, were classified as $P 1^{i}$.

Anti-P1 phage serum. The same antiserum described in a previous paper was used (16).

Bacterial crosses by mixed cultivation. At various times of incubation, after mixing donor and recipient cultures, suitable samples of the mixture were spread on appropriate selective plates, on which neither of the parent strains could grow alone. The frequency of transfer in a particular cross was determined by dividing the number of colonies which appeared on the selective plate by the number of donor cells in the initial mating mixture.

Sensitivity of bacteria to phage. A loopful of phage stock (ca. $10^{9}$ phage per milliliter) was spotted onto a bacterial lawn seeded on EMB complete agar without sugar.

Method of treatment with acridine dye. Overnight L-broth cultures of test strains were inoculated into L-broth ( $p \mathrm{H} \mathrm{7.8)} \mathrm{containing} \mathrm{acridine} \mathrm{dye} \mathrm{in} \mathrm{various}$ concentrations (12). After overnight incubation, the cells were plated on bromothymol blue-lactose-nutrient agar, and the CM resistance of the colonies which developed on incubation was tested. The test for the presence of the $F$ factor was based on $f$ phage sensitivity after three successive single-colony isolations of the colony.

\section{RESULTS}

Infection of Salmonella strains by phage P1CM. After incubation of $S$. typhi $\mathrm{H} 901$ with a P1CM lysate prepared on an $E$. coli $\mathrm{F}^{+} L p^{+}$host, $S$. typhi $\mathrm{H} 901$ clones carrying $\mathrm{P} 1$ and resistant to CM could be isolated. Other strains of Salmonella, S. abony 74 and S. typhimurium LT2, were similarly tested, but, as shown in Table 2 , only $S$. typhi and $S$. abony could be transduced with P1CM. Transduction frequencies were about $10^{-6}$ to $10^{-7}$ per input phage or about $10^{-8}$ per input cell. P1CM lysates derived from $\mathrm{F}^{-} L p^{-}$strains can transduce the Salmonella strains with the same efficiency as that of P1CM lysates derived from the $\mathrm{F}^{+} L p^{+}$strain. This indicates that neither the $F$ factor nor $\lambda$ phage carried by a donor cell contributes to this system. Moreover, the formation of CM-resistant Salmonella colonies could be inhibited completely by prior treatment with anti-P1 phage serum. 
TABLE 2. Infection of PICM phage in Salmonella and formation of CM-resistant strains*

\begin{tabular}{|c|c|c|c|c|c|c|c|}
\hline \multirow{2}{*}{ Prepn } & \multirow{2}{*}{$\begin{array}{l}\text { Plaque- } \\
\text { forming } \\
\text { units } / \mathrm{ml}\end{array}$} & \multicolumn{2}{|r|}{ S. typhi } & \multicolumn{2}{|r|}{ S. abony } & \multicolumn{2}{|c|}{$\underset{\text { typhimurium }}{S .}$} \\
\hline & & MOI & No. $\mathrm{CM}^{\mathbf{r}}$ & MOI & No. $\mathbf{C M}^{\mathrm{r}}$ & MOI & No. \\
\hline $\begin{array}{l}\text { Lysate prepared by propagating UV- } \\
\text { induced P1CM from } E \text {. coli } \operatorname{Tr} 62- \\
3 \text {, on } E \text {. coli } \mathrm{F}^{+}\end{array}$ & $8.4 \times 10^{9}$ & 0.3 & $\left(3.6 \times^{6} 10^{-7}\right)$ & 0.4 & $\left(3.6 \times 10^{-7}\right)$ & 0.1 & 0 \\
\hline $\begin{array}{l}\text { Lysate prepared by propagating UV- } \\
\text { induced P1CM from } E \text {. coli } \operatorname{Tr} 62- \\
3 \text {, on } E \text {. coli } 3110\end{array}$ & $1.5 \times 10^{10}$ & 0.5 & $\frac{14}{\left(4.8 \times 10^{-7}\right)}$ & 0.3 & $\stackrel{25}{\left(8.6 \times 10^{-7}\right)}$ & 0.2 & 0 \\
\hline $\begin{array}{l}\text { Lysate prepared by propagating } \\
\mathrm{P} 1 C M \text { released from } E \text {. coli } \mathrm{Tr} 30- \\
5 \text {, on } E \text {. col } i \mathrm{~F}^{+}\end{array}$ & $7.0 \times 10^{9}$ & 0.3 & $\left(5.7 \times 10^{-7}\right)$ & 0.1 & $\left(5.7 \times^{8} 10^{-7}\right)$ & 0.1 & 0 \\
\hline
\end{tabular}

* Each $0.2 \mathrm{ml}$ of a $10^{-1}$ dilution of phage lysates, and each $1.8 \mathrm{ml}$ of bacterial culture $(S$. typhi, $3.1 \times$ $10^{8}$ cells per milliliter; $S$. abony, $6.6 \times 10^{8} ; S$. typhimurium LT2, $9.6 \times 10^{8}$ ) containing $3 \times 10^{-3} \mathrm{M} \mathrm{CaCl}_{2}$, were mixed and incubated for $90 \mathrm{~min} ; 0.2 \mathrm{ml}$ of the mixture was spread on Heart Infusion Agar containing CM $(25 \mu \mathrm{g} / \mathrm{ml})$, and the number of colonies which developed were counted after $48 \mathrm{hr}$ of incubation. Figures in parentheses show the transduction frequency expressed as the number of $C M^{\mathrm{r}}$ colonies per number of input phage. MOI, multiplicity of infection.

The CM-resistant colonies of $S$. typhi and $S$. abony were purified by four successive singlecolony isolations, and were tested for P1 lysogeny. They were all found to be lysogenic. The spontaneous loss of the $C M^{\mathrm{r}}$ character was examined in five $C M^{\mathrm{r}}$ clones of each Salmonella strain. Tests on 200 to 600 colonies of each clone showed that they were all $C M^{\mathrm{r}}$. It was found, furthermore, that P1CM was very stable in these clones and was not lost on repeated subculturing or on aging.

These results indicate that some Salmonella strains are able to be infected with P1CM phage and that they can give rise to stable phage carriers, just as in lysogeny.

Transduction frequencies by P1CM are usually more than 0.5 when $E$. coli strains are the recipients. In contrast, the frequency of $10^{-6}$ to $10^{-7}$ observed in Salmonella strains is very low. It seemed useful, therefore, to measure the efficiency of adsorption of P1CM. Phage was mixed with bacteria (ratio of about 1:10) in the presence of $\mathrm{CaCl}_{2}\left(2.5 \times 10^{-3} \mathrm{M}\right)$, and the mixture was allowed to stand for $20 \mathrm{~min}$ at $37 \mathrm{C}$. The mixture was then diluted with cold fresh L-broth, and was plated with $S$. dysenteriae $\mathrm{Sh} / \mathrm{s}$ on L-broth agar containing SM $(200 \mu \mathrm{g} / \mathrm{ml})$ for plaque formation of unadsorbed phage. From 15 to $25 \%$ of the added P1CM was adsorbed to S. typhi $(95$ to $98 \%$ was adsorbed to $E$. coli). Though its rate is very low, compared with $E$. coli, S. typhi adsorbs significant numbers of phage P1CM particles. However, $S$. typhi fails to show plaque formation with P1CM, even when very large numbers of phage particles were used.

To test whether pháge infection of S. typhi is due to a host-range mutant, plaque formation and transduction frequency were assayed on $S$. typhi $\mathrm{H} 901$ by use of P1CM recovered from the $S$. typhi $\mathrm{P} \mathrm{CM}^{+}$strain, ML 1154 . No plaques were produced when the phage lysate was plated on $S$. typhi and, in addition, this phage transduced $S$. typhi to $C M^{\mathrm{r}}$ at a frequency similar to the original P1CM derived from E. coli. Therefore, the infection of P1CM in Salmonella is not explainable by a special phage mutant, and, after the infection of Salmonella, the phage does not exhibit a host-induced modification in host range.

To determine whether the phenomenon was caused by a P1CM mutant with an increased rate of adsorption for the Salmonella strain, adsorption efficiency of phage released by $\mathrm{Sal}$ monella was measured on ML 1154. In general, lysogenized strains show the same capacity to adsorb the lysogenic phage as do the nonlysogenized original strains. It was observed that about $80 \%$ of input P1 or P1CM remained unadsorbed, as shown initially for the original $S$. typhi $\mathrm{H} 901$ strain. In the case of $E$. coli $\mathrm{K}-12$ $\mathrm{P} \mathrm{CM}^{+}$, more than $95 \%$ of input P1 or P1CM was adsorbed to the cells.

These results indicate that the infection of $S$. typhi by P1CM is not due to a special mutant of Salmonella which has a higher capacity to adsorb phage P1CM.

Formation of F-CM element. Upon mixed 
incubation of $S$. typhi with cells of $E$. coli $\mathrm{Tr}$ 30-5 $\left(\mathrm{F}^{+} \mathrm{P} 1 C M^{+}\right)$, S. typhi $C M^{\mathrm{r}}$ cells were obtained. In the course of purification, it was observed that some $S$. typhi $C M^{\mathrm{r}}$ clones gave reddish colonies on EMB medium without sugar; such reddening was lost upon subculturing, as reported by Zinder (33).

Among 22 clones of $S$. typhi $C M^{\mathrm{r}}, 7$ clones were phage producers, as might be obtained from infection by P1CM phage, but 15 clones did not release phage. Among these 15 clones, 13 were incapable of transferring the $C M^{\mathrm{r}}$ character to $E$. coli $\mathrm{W} 4574 / \mathrm{P} 1$ and to W2984/P1, even after $6 \mathrm{hr}$ of incubation. One of these 13 clones, S. typhi $C M^{\mathrm{r}}$ (St-3), was subjected to further investigation of its ability to transfer the $C M^{\mathbf{r}}$ character to the following recipients; $E$. coli $\mathrm{K}-12 \mathrm{~F}^{+}$, W1895 Hfr, W4574 F-, W3630 क 3 (30), 58-161 $\mathrm{F}^{-}$, and W2984 $\mathrm{F}^{-}$. It was found that only $E$. coli $\mathrm{F}^{+}$became $C M^{\mathbf{r}}$ after mixed cultivation with St-3. $C M^{\mathbf{r}}$ clones appeared at a very low frequency, one to two clones per $10^{8}$ parent cells after $48 \mathrm{hr}$ of incubation. One of the $E$. coli $\mathrm{F}^{+}$ $C M^{\mathbf{r}}$ isolates thus obtained was designated as $E$. coli $\mathrm{K} 57$. E. coli $\mathrm{K} 57$ was able to transfer its $C M^{\mathrm{r}}$ character at extremely high frequency (ca. $10^{\circ}$ ) and to produce pro $^{+}$recombinants at a frequency of $10^{-5}$, in mixed cultivation with $E$. coli W4574. The transfer frequency of the $C M^{\mathrm{r}}$ character was comparable to that of the $\mathrm{F}$ factor (17), though the transfer frequency of $\mathbf{R}$ factors is usually found to be $10^{-3}$ to $10^{-4}$ under our experimental conditions. The transfer of genetic markers other than $C M^{\mathrm{r}}$ was also examined (Table 3). These results indicate that the $C M^{\mathrm{r}}$ character is transferred in extremely high frequency, independent of chromosomal transfer, and that $C M^{\mathrm{r}}$ recipients are also all $\mathrm{F}^{+}$, as shown by their sensitivity to $f$ phages.

To elucidate the mechanisms of joint transfer of $\mathrm{F}$ and $C M^{\mathrm{r}}$ characters at high frequency, two experiments were performed, one involving transduction with phage $P 1$ and the other involving treatment with acridine.

$C M^{\mathrm{r}}$ transductants of $E$. coli $\mathrm{K}-12 \mathrm{~W} 3110$ and PA 200 were obtained by phage P1 grown on $E$. coli $\mathrm{K} 57$ at a multiplicity of infection of 0.2 , and they were tested for $f$ phage sensitivity. It was found that $92.5 \%$ of these were $\mathrm{F}^{+}$(Table 4 ). Accordingly, it was concluded that the $\mathrm{F}$ factor was transduced jointly with the $C M^{\mathrm{r}}$ character in most cases. Moreover, as shown in Table 5, $90 \%$ of $E$. coli $\mathrm{K} 57$ cells lost the $C M^{\mathbf{r}}$ character after treatment with acridine orange; these clones were all $\mathrm{f}$ phage-resistant. In contrast, $C M^{\mathrm{r}}$ clones were all sensitive to $f$ phage. Wild-type $R$ factors in $E$. coli are eliminated by treatment with acridine dye (25), but the frequency (less than a few per cent) is extremely low compared with that of $F$ factor, which is nearly $100 \%$ (12).

From the fact that the $C M^{\mathrm{r}}$ character is consistently associated with the $F$ factor, we conclude that these two characters have become a single unit, forming a complex, the F-CM factor

Isolation of $S$. typhi strains carrying PIdCM and $F$, which are susceptible to $f$ phages. Of 15 clones of $S$. typhi $C M^{\mathrm{r}}$ which did not release active P1CM phage, 2 clones (St-1 and St-22) were found to be capable of transferring their $C M^{\mathrm{r}}$ character to $E$. coli $\mathrm{F}^{-}$at high frequencies (about $10^{-3}$ ).

The $C M^{\mathrm{r}}$ and $\mathrm{F}$ determinants in these $S$. typhi strains were transferred to $E$. coli $\mathrm{K}-12$ strains W2984, 58-161 $\mathrm{F}^{-}$, and wild $\mathrm{F}^{-}$by mixed cultivation. The $E$. coli strains carrying $\mathrm{F}$ and $C M^{\mathrm{r}}$ derived from St-1 were all negative by the P1 lysogeny test, but were immune to phage P1. On the other hand, $E$. coli strains carrying $F$ and $C M^{\mathrm{r}}$ derived from $\mathrm{St}-22$ were all positive by the P1 lysogeny test, producing a small faint plaque on the P1 indicator strain. We then tested whether any P1CM-related particles, i.e., P1 plaque-forming or $C M^{\mathrm{r}}$-transducing particles, existed in cell-free lysates of these strains before or after UV irradiation. The results (Table 6) revealed that strains carrying $\mathrm{F}$ and $C M^{\mathrm{r}}$ derived from St-1 liberated neither P1-plaque-forming nor $C M^{\mathrm{r}}$-transducing particles, but $E$. coli carrying $\mathrm{F}$ and $C M^{\mathrm{r}}$ derived from St-22 spontaneously liberated faint plaque-forming and $C M^{\mathrm{r}}$-transducing particles. In the original Salmonella strains, $C M^{\mathrm{r}}$ transductants did not appear, even when normal P1 phage was added as helper to the transduction mixture. However, as shown in Table 4, upon superinfection with virulent P1 phage, $E$. coli strains carrying $\mathrm{F}$ and $C M^{\mathrm{r}}$ derived from St-1 yielded a lysate which gives $C M^{\mathrm{r}}$. transduction at a frequency of about $10^{-2}$, which is considered high frequency of transduction (HFT) according to terminology of Morse et al. (28).

These results indicate that these $E$. coli strains, and possibly St-1, possess a defective P1CM element, or a P1 defective $C M$ element according to the terminology used in certain other transduction systems, for example, $\lambda d g(2,7)$, P1dl (22), $\phi 80 d t$ (24), and $\epsilon_{15} d R_{23}$ (14).

The results of plaque-center tests (16), shown in the far-right column of Table 6 , indicated that the plaque-forming particles released from $E$. coli carrying $\mathrm{F}$ and $C M^{\mathrm{r}}$ derived from St-22 possess $C M^{\mathrm{r}}$-transducing ability. In addition, the $C M^{\mathrm{r}}$ transductants obtained with the lysate from an overnight culture of the $E$. coli strain showed the 
TABLE 3. Genetic constitution of recombinants from a cross between Escherichia coli W4574 and E. coli K57

\begin{tabular}{|c|c|c|c|c|c|c|c|c|c|c|c|c|}
\hline \multirow{2}{*}{$\begin{array}{l}\text { Inbucation time } \\
\text { for cross }\end{array}$} & \multirow{2}{*}{$\begin{array}{c}\text { Selective } \\
\text { marker }\end{array}$} & \multirow{2}{*}{$\begin{array}{l}\text { No. of } \\
\text { clones }\end{array}$} & \multicolumn{10}{|c|}{ Character } \\
\hline & & & lac & pro & ara & $m t l$ & $x y l$ & mal & gal & $C M$ & $S M$ & f1 \\
\hline$h r$ & & & & & & & & & & & & \\
\hline 1 & pro & $\begin{array}{l}3 \\
1\end{array}$ & $\begin{array}{l}- \\
-\end{array}$ & $\begin{array}{l}+ \\
+\end{array}$ & $\bar{t}$ & - & - & - & - & $\begin{array}{l}\mathbf{r} \\
\mathbf{r}\end{array}$ & $\begin{array}{l}\mathbf{r} \\
\mathbf{r}\end{array}$ & $\begin{array}{l}\mathbf{s} \\
\mathbf{s}\end{array}$ \\
\hline 2 & pro & $\begin{array}{l}3 \\
5\end{array}$ & - & $\begin{array}{l}+ \\
+\end{array}$ & $\bar{t}$ & - & - & $\overline{-}$ & - & $\begin{array}{l}\mathbf{r} \\
\mathbf{r}\end{array}$ & $\begin{array}{l}\mathbf{r} \\
\mathbf{r}\end{array}$ & $\begin{array}{l}\mathbf{S} \\
\mathbf{S}\end{array}$ \\
\hline $0^{*}$ & $\mathrm{CM}$ & 20 & - & - & - & - & - & - & - & $r$ & $\mathbf{r}$ & $\mathbf{s}$ \\
\hline
\end{tabular}

* The conjugation mixture was plated on selective medium immediately after mixing both donor and recipient.

TABLE 4. Transduction of $C M^{\mathrm{r}}$ character with phage PI

\begin{tabular}{|c|c|c|c|c|}
\hline Escherichia coli donor strain & $\begin{array}{l}\text { E. coli recipient } \\
\text { strain }\end{array}$ & MOI & $\begin{array}{c}\text { Transduction frequency } \\
\text { per input phage }\end{array}$ & $\begin{array}{l}\text { Phage f1-sensitive } \\
\text { clones per no. tested }\end{array}$ \\
\hline $\begin{array}{l}\mathrm{K} 57(\mathrm{~F}-C M)^{+} \ldots \ldots \\
\mathrm{K} 57(\mathrm{~F}-C M)^{+} \ldots \ldots \\
\text { W2984 } \mathrm{F}^{+} \mathrm{P} 1 d C M_{\mathrm{St}-1}^{+*} \ldots \ldots \\
\text { Wild } \mathrm{F}^{+} \mathrm{P} 1 d C M_{\mathrm{St-1}}^{+*} \ldots \ldots \ldots \\
\text { W2984 } \mathrm{F}^{+} \mathrm{P} 1 d C M_{\mathrm{St}-22}^{+*} \ldots \ldots \\
\text { wild } \mathrm{F}^{+} \mathrm{P} 1 d C M_{\mathrm{St}-22}^{+*} \ldots \ldots \ldots\end{array}$ & $\begin{array}{l}\text { W3110 } \\
\text { PA200 } \\
\text { PA200 } \\
\text { W3110 } \\
\text { PA200 } \\
\text { W3110 }\end{array}$ & $\begin{array}{r}0.2 \\
0.2 \\
0.1 \\
10^{-5} \\
10^{-3} \\
10^{-5}\end{array}$ & $\begin{array}{l}2 \times 10^{-6} \\
6 \times 10^{-6} \\
\text { ca. } 10^{-1} \\
3 \times 10^{-2} \\
\text { ca. } 10^{-1} \\
9 \times 10^{-3}\end{array}$ & $\begin{array}{r}37 / 40 \\
37 / 40 \\
0 / 39 \\
0 / 40 \\
0 / 39 \\
0 / 40\end{array}$ \\
\hline
\end{tabular}

* These are $E$. coli strains carrying $\mathrm{F}$ and $\mathrm{CM}^{\mathrm{r}}$ derived from St-1 and St-2.

TABLE 5. Elimination of $C M^{\mathrm{r}}$ character by treatment with acridine orange

\begin{tabular}{|c|c|c|c|}
\hline \multirow{2}{*}{ Strain } & \multirow{2}{*}{ Type of $\mathrm{CM}^{\mathbf{r}}$} & \multicolumn{2}{|c|}{ Concn of acridine orange } \\
\hline & & $100 \mu \mathrm{g} / \mathrm{ml}$ & 0 \\
\hline $\begin{array}{l}\text { Escherichia coli } \mathrm{K} 57 \ldots \ldots \ldots \ldots \ldots \\
\text { Salmonella typhi } \mathrm{St}-1 \ldots \ldots \ldots \\
\text { S. typhi } \mathrm{St}-22 \ldots \ldots \ldots \ldots \ldots \ldots \ldots \\
\text { S. } \text { typhi } \mathbf{S t}-3 \ldots \ldots \ldots \ldots \ldots \ldots \\
\text { E. coli } \mathrm{F}^{+} \mathrm{R}_{14}+\ldots \ldots \ldots \ldots \ldots \ldots\end{array}$ & $\begin{array}{l}\text { F-CM } \\
\text { P1 } d C M \\
\text { P1dCM } \\
\text { Nontransmissible } \mathrm{CM}^{\mathbf{r}} \\
\text { R factor }\end{array}$ & $\begin{aligned} 99 / 110 & (90 \%) \\
0 / 687 & \\
0 / 309 & \\
7 / 471 & (1.8 \%) \\
1 / 393 & (0.3 \%)\end{aligned}$ & $\begin{array}{l}0 / 280 \\
0 / 180 \\
0 / 360 \\
0 / 420 \\
0 / 326\end{array}$ \\
\hline
\end{tabular}

same small faint plaque in the P1 lysogeny test. This particle is considered to be slightly defective in $\mathrm{P1}$ phage function, because its plaque is so small and faint. Also, an E. coli strain carrying this particle shows less immunity to superinfection by $\mathbf{P} 1$, as evidenced by the fairly high titer of $\mathbf{P} 1$ lysates (about $10^{9}$ per milliliter) obtained from these strains after superinfection.

Thus, this particle derived from St-22 is also a defective P1CM, although the degree of its defectiveness is less than that of P1dCM in St-1. These elements are designated as $\mathrm{P} 1 d C M_{\mathrm{St}-22}$ and $\mathrm{P} 1 d C M_{\text {st-1 }}$, respectively.

It was also shown that the $C M^{\mathrm{r}}$ character in St-1 and St-22, and in $E$. coli strains carrying the $\mathrm{F}$ and $C M^{\mathrm{r}}$ characters which were derived from the $S$. typhi strains, could be transferred to either E. coli $\mathrm{F}^{-} \mathrm{W} 4574$ or $\mathrm{W} 4574 / \mathrm{P} 1$ at a high frequency (Table 7). However, although $C M^{\mathrm{r}}$ recipients are not all $\mathrm{F}^{+}$, they are all $\mathrm{P}^{\mathrm{i}}$. It was further observed that acridine dye treatment failed to eliminate the $C M^{\mathrm{r}}$ character of both $S$. typhi strains, St-1 and St-22 (Table 5); the $C M^{\mathrm{r}}$ transductants were all resistant to f1 phage (Table 4), being different from those of $E$. coli K57. These facts suggest that the $C M^{\mathrm{r}}$ and $\mathrm{F}^{+}$determinants in St-1 and St-22 are not linked to each other, and that they probably exist separately as different elements. St-1 and St-22 themselves were susceptible to $f$ phages, and $f$ phages produce plaques on these strains with the same efficiency of plating as on the $E$. coli male strains. 
TABLE 6. PICM-related particle in cell-free supernatant fluid of culture*

\begin{tabular}{|c|c|c|c|c|c|}
\hline \multirow{2}{*}{ Strain } & \multicolumn{3}{|c|}{ No. of $\mathrm{CM}^{\mathrm{r}}$ transductants } & \multirow{2}{*}{$\begin{array}{c}\text { Plaque } \\
\text { formation }\end{array}$} & \multirow{2}{*}{$\begin{array}{l}\text { No. of } \mathrm{CM}^{\mathrm{r}} \text { per no. } \\
\text { of of plaques tested }\end{array}$} \\
\hline & $\begin{array}{l}\text { Overnight L- } \\
\text { broth culture }\end{array}$ & $\begin{array}{l}\text { UV-induced } \\
\text { culture }\end{array}$ & $\begin{array}{c}\text { UV-induced culture } \\
+ \text { helper P1 }\end{array}$ & & \\
\hline 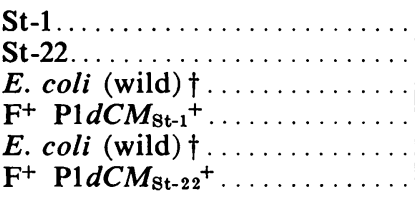 & $\begin{array}{l}0 \\
0 \\
0\end{array}$ & $2 \times 10^{4}$ & $2 \times 10^{4}$ & $\begin{array}{l}- \\
-\end{array}$ & $87 / 92$ \\
\hline
\end{tabular}

* An overnight L-broth culture was centrifuged. The supernatant fluid was used as the "overnight culture"; the sedimented cells were suspended in saline, and were subjected to UV induction (16). The supernatant fluid, after incubation for $90 \mathrm{~min}$, was used as the "UV-induced culture." The transduction mixture contained $0.1 \mathrm{ml}$ of lysate after chloroform treatment, $0.5 \mathrm{ml}$ of an E. coli $\mathrm{K}-12 \mathrm{~F}^{+}$ (wild) culture containing $5 \times 10^{-3} \mathrm{M} \mathrm{CaCl}_{2}\left(5 \times 10^{8}\right.$ cells per milliliter) and $0.1 \mathrm{ml}$ of $\mathrm{L}$ broth or normal P1 lysate $\left(7 \times 10^{8}\right.$ cells per milliliter $)$ as a helper. After 20 min of incubation, $0.2 \mathrm{ml}$ of the mixture was spread on $\mathrm{L}$ broth-agar containing $\mathrm{CM}(25 \mu \mathrm{g} / \mathrm{ml})$. The results are expressed as the number of transductants per milliliter of lysate added.

$\dagger$ These are the same strains as used in Table 4.

TABLE 7. Transfer of CMr character by conjugation*

\begin{tabular}{|c|c|c|c|c|c|}
\hline Donor & $\begin{array}{l}\text { E. coli } \\
\text { recipient }\end{array}$ & $\begin{array}{l}\text { No. of } \mathrm{CM}^{\mathrm{r}} \\
\text { recipient }\end{array}$ & $\begin{array}{l}\text { Transfer } \\
\text { frequency }\end{array}$ & $\begin{array}{l}\text { Phage f1-sensi- } \\
\text { tive clones per no. } \\
\text { tested }\end{array}$ & $\begin{array}{l}\text { P1-immune } \\
\text { clones } \\
\text { per no. tested }\end{array}$ \\
\hline Salmonella typhi $\mathrm{St}-1 \ldots$ & W4574 & $9 \times 10^{2}$ & $10^{-5}$ & $15 / 19$ & $19 / 19$ \\
\hline Escherichia coli (wild) $\mathrm{F}^{+}$ & W4574/P1 & $1.7 \times 10^{3}$ & $10^{-5}$ & & \\
\hline \multirow[t]{2}{*}{$\mathrm{P} 1 d C M_{\mathrm{St}-1}+\dagger \ldots \ldots \ldots \ldots \ldots \ldots$} & W4574 & $3.7 \times 10^{6}$ & $10^{-2}$ & & \\
\hline & W4574/P1 & $5.0 \times 10^{6}$ & $10^{-2}$ & & \\
\hline \multirow[t]{2}{*}{ S. typhi St-22. } & W4574 & $1.9 \times 10^{5}$ & $10^{-3}$ & $19 / 20$ & $20 / 20$ \\
\hline & W4574/P1 & $5.2 \times 10^{5}$ & $10^{-3}$ & & \\
\hline \multirow[t]{2}{*}{ E. coli (wild) $\mathrm{F}^{+} \mathrm{P} 1 d C M_{\mathrm{St}-22^{+}}+\ldots$} & W4574 & $1.6 \times 10^{6}$ & $10^{-2}$ & & \\
\hline & W4574/P1 & $9.8 \times 10^{5}$ & $10^{-2}$ & & \\
\hline
\end{tabular}

${ }^{*}$ Equal volumes of L-broth overnight culture $\left(2 \times 10^{8}\right.$ to $5 \times 10^{8}$ cells per milliliter $)$ of donor and recipient strains were mixed and incubated for $2 \mathrm{hr} ; 0.1 \mathrm{ml}$ of appropriate dilutions were plated on bromothymol blue-lactose-nutrient agar containing CM $(25 \mu \mathrm{g} / \mathrm{ml})$ and SM $(200 \mu \mathrm{g} / \mathrm{ml})$.

$\dagger$ These are the same strains as used in Table 4

S. typhi strains, i.e., St-1, St-22, and St-3, exhibited the same biochemical and serological properties as $S$. typhi $\mathrm{H} 901$.

\section{Discussion}

In $E$. coli $\mathrm{K}-12$ strains it has been established that male strains, $\mathrm{F}^{+}, \mathrm{F}^{\prime}$, or $\mathrm{Hfr}$, can donate their chromosomal characters and cytoplasmic elements to other bacterial cells by conjugation. $\mathbf{R}$ factors are genetic elements which resemble the $F$ factor in many respects, although positive evidence for the integration of $\mathrm{R}$ factors in a host chromosome has not yet been shown. $\mathrm{R}$ factors are mutually transmissible to a wide range of strains belonging to the Enterobacteriaceae (10) and Vibrio (4).

The results presented in this paper revealed that phage P1CM infected certain cells of $S$. typhi and established a phage-host relationship analogous to lysogeny. However, the adsorption efficiency of P1CM to $S$. typhi is fairly low. Also, the P1CM released from $S$. typhi $\mathrm{P} 1 C M^{+}$ failed to show infectious centers on $S$. typhi or an increased ability to transduce the $C M^{\mathrm{r}}$ character to $S$. typhi over that of original P1CM. Therefore, the infection of P1CM on $S$. typhi is probably not due to a host-range mutation (20) nor to a hostinduced modification of the phage (21).

Moreover, since the $S$. typhi $\mathrm{P} 1 C M^{+}$strain $\mathrm{ML}$ 1154 shows no increased capacity to adsorb P1CM over that of the original S. typhi strain, the infection by P1CM of $S$. typhi is not due to a special bacterial mutation which has a higher capacity to adsorb the phage. That $S$. typhi re- 
ceives the P1CM phage genome may be considered to be analogous to the ability of this organism to mate with $E$. coli. The fact that $S$. typhi $\mathrm{P} 1 \mathrm{CM}^{+}$does not show a high capacity to adsorb the phage is similar to the situation in which $S$. typhi strains exhibit a low but homogeneous ability of its population to mate initially with $E$. coli $\mathrm{Hfr}$ donors (13). In $S$. typhimurium LT7 $\mathrm{mut}^{+}$, it was demonstrated that fertile recipients are present in the majority of a sterile population (26). S. typhimurium LT2 was found to be infertile, and it mated only infrequently. In $S$. abony, some $\mathrm{Hfr}$ strains were isolated from the clones which had become $\mathrm{F}^{+}$by receiving the $\mathrm{F}$ factor from $E$. coli (23). The infection of P1CM in Salmonella strains was found in S. typhi and $S$. abony, but not in $S$. typhimurium LT2.

When $E$. coli $\mathrm{F}^{+} \mathrm{P} C_{M^{+}}$was subjected to conjugation with $S$. typhi $\mathrm{H} 901$, three types of $S$. typhi $C M^{\mathrm{r}}$ clones were obtained: clones carrying P1CM phage, clones carrying P1-defective $C M$ elements, and clones carrying only nontransmissible $C M^{\mathrm{r}}$. The second type was found to carry simultaneously the $F$ factor, but the failure of the $C M^{\mathrm{r}}$ element to be transduced jointly with the $\mathrm{F}$ character or to be eliminated together by treatment with acridine dye indicated that these two determinants exist separately. One of the third type of $S$. typhi $C M^{\mathrm{r}}$ clones, St-3, showed about a $2 \%$ loss of its $C M^{\mathrm{r}}$ character upon treatment with acridine, and its $C M^{\mathrm{r}}$ character was not transferred by conjugation. However, the $C M^{\mathrm{r}}$ character in St-3 acquired the ability to be transferred by conjugation when the strain was crossed with an $E$. coli $\mathrm{F}^{+}$strain. From the experimental results of joint transduction or joint elimination with acridine treatment, it was concluded that the $C M^{\mathrm{r}}$ character had been associated with the $\mathrm{F}$ factor, forming an F-CM factor, thereby gaining transferability. The proposed genetic element, the F-CM factor, is a kind of $F^{\prime}(1,11)$, though the proposed mechanism for the origination of the usual $\mathrm{F}^{\prime}$ may not apply in the case of F-CM. The ordinary $\mathrm{F}^{\prime}$ strains are derived from integrated $\mathrm{F}$ factors, and they carry the chromosomal character(s) which may be adjacent to the $\mathrm{F}$ factor. In the case of F-CM, it is likely that the association of both determinants took place in the cytoplasmic state, because the $C M^{\mathrm{r}}$ character in St-3 is presumably in the cytoplasmic state as indicated by the results of acridine dye treatment.

Since the $C M^{\mathrm{r}}$ character in $\mathrm{St}-3$ could be associated with transferability in $\mathrm{F}^{+}$strains but not in $\mathrm{Hfr}$ or $\mathrm{F}^{-}$, it seems that there are three steps in the acquisition of this transferability: infection of the $\mathrm{F}$ factor from the recipient to donor, an association of the $\mathrm{F}$ factor with the $C M^{\mathrm{r}}$ determi- nant in the donor cell, and transfer of the formed F-CM element to the recipient.

Two $S$. typhi P1dCM+ strains were isolated which carry the $F$ determinant. It remains obscure as to whether the $\mathrm{F}$ factor has any correlation with the carrying of P1dCM by these strains. An experiment to determine whether the $C M^{\mathrm{r}}$ characters in the third type of $S$. typhi $C M^{\mathrm{r}}$ clones are present as a form of P1dCM is impossible at present because of technical limitations.

As a consequence of conjugation between $S$. typhi and $E$. coli $\mathrm{F}^{+}$lysogenic for P1CM, S. typhi strains carrying P1dCM elements were ob. tained. Two P1dCM elements were found to vary in their P1 functions, as noted by the difference in their ability to initiate maturation and interference with the function of normal P1 phage. The diversity of the phage-specific properties of various P1 $d l$ elements has been reported by Luria et al. (22).

By means of conjugal transfer from St-22 to $E$. coli, the P1dCM element acquired the capa. bility to initiate maturation. The mechanism is obscure at present, but one possibility is that this ability might have been gained by rescue with the genetic material of $E$. coli, since the genetic material of phage P1 is more homologous with $E$. coli than $S$. typhi.

The present and previous (16) studies demonstrate the alternate association of the $C M^{\mathrm{r}}$ determinant derived from an $\mathbf{R}$ factor with different genetic elements, first with phage $P 1$ and then with the $F$ factor. The hybrid elements formed are very stable and behave in several instances as a single unit after the association has occurred. Thus, the genetic interaction between three kinds of episomic elements, the $F$ and $R$ factors, and prophage $P 1$ has been established.

It was reported from this laboratory (9) that the nontransferable R(TC) character, obtained by transduction with $\epsilon$ phage and integrated on the host chromosome, acquired conjugational transferability by the formation of $\mathrm{F}-(T C)$.

Infection of Salmonella strains by $\mathrm{F}$ and $\mathrm{F}^{\prime}$ factors, and their hybridization with $E$. coli strains, have been reported $(3,27,32,33)$. The presence of sex factors in Salmonella was recognized by the ability of these strains to transfer the factors back to $E$. coli, or by mating with other strains of Salmonella. Zinder (33) proposed a staining method for following the transfer of the F agent to Salmonella, but it was noted that $\mathrm{F}^{+}$Salmonella did not give a positive reaction. Although production of male substances (29) by the hybrid of Salmonella with $E$. coli was observed $(8,23)$, susceptibility of these hybrid strains to $f$ phage was not demonstrated. In this paper, 
it was shown that $S$. typhi carrying the F factor is susceptible to f phages.

\section{ACKNOWLEDGMENTS}

We thank H. Ozeki for many valuable discussions, and L. S. Baron and S. Falkow for help in the preparation of this manuscript.

This investigation was supported by a research grant from the Waksman Foundation of Japan.

\section{Literature Cited}

1. Adelberg, E. A., ANd S. N. Burns. 1959. A variant sex factor in Escherichia coli. Genetics 44:497.

2. Arber, W., G. Kellenberger, and J. Weigle. 1957. La défectuosité du phage lambda transducteur. Schweiz. Z. Allgem. Pathol. Bacteriol. 20:659-665.

3. Baron, L. S., W. F. Carey, and W. M. Spllman. 1958. Hybridization of Salmonella species by mating with Escherichia coli, p. 50. In Recent progress in microbiology, Intern. Congr. Microbiol. 7th, Stockholm.

4. Baron, L. S., and S. Falkow. 1961. Genetic transfer of episomes from Salmonella typhosa to Vibrio cholerae. Records Genetics Soc. Am. $30: 59$.

5. Bertani, G. 1958. Lysogeny. Advan. Virus Res. 5:151-193.

6. Bertani, G., and S. J. Nice. 1954. Studies on lysogenesis. II. The effect of temperature on the lysogenization of Shigella dysenteriae with phage P1. J. Bacteriol. 67:202-209.

7. CAMPBell, A. 1957. Transduction and segregation in $E$. coli $\mathrm{K}-12$. Virology 4:366-384.

8. Falkow, S., and L. S. Baron. 1962. Episomic element in a strain of Salmonella typhosa. J. Bacteriol. 84:581-589.

9. Harada, K., M. Kameda, M. Suzuki, and S. MitsuHASHI. 1964. Drug resistance of enteric bacteria. III. Acquisition of transferability of nontransmissible $\mathbf{R}(\mathrm{TC})$ factor in cooperation with $F$ factor and formation of $F R(T C)$. J. Bacteriol. 88:1257-1265.

10. Harada, K., M. Suzuki, M. Kameda, and S. MrTSUHASHI. 1960. On the drug-resistance of enteric bacteria. 2. Transmission of the drugresistance among Enterobacteriaceae. Japan J. Exptl. Med. 30:289-299.

11. Hirota, Y. 1959. Mutants of the F-factor in Escherichia coli K-12. Genetics 44:515.

12. Hirota, Y. 1960. The effect of acridine dyes on mating type factors in E. coli. Genetics 46:5764.

13. Johnson, E. M., S. Falkow, and L. S. Baron. 1964. Recipient ability of Salmonella typhosa in genetic crosses with Escherichia coli. J. Bacteriol. 87:54-60.

14. Kameda, M., K. Harada, M. Suzuki, and S. MrTsuHASHI. 1965. Drug resistance of enteric bacteria. V. High frequency of transduction of
R factors with bacteriophage epsilon. J. Bac. teriol. 90:1174-1181.

15. Kondo, E., K. Harada, and S. Mitsuhashi. 1962. Transduction of the transmissible drug resistance factor by bacteriophage P1kc. Japan. J. Exptl. Med. 32:139-147.

16. Kondo, E., AND S. Mitsuhashi. 1964. Drug resistance of enteric bacteria. IV. Active transducing bacteriophage P1 $C M$ produced by the combination of $\mathbf{R}$ factor with bacteriophage P1. J. Bacteriol. 88:1266-1276.

17. Lederberg, J., L. L. Cavalli, and E. M. LederBERG. 1952. Sex compatibility in E. coli. Genetics 37:720-730.

18. LOEB, T. 1960. Isolation of a bacteriophage specific for the $\mathrm{F}^{+}$and $\mathrm{Hfr}$ mating types of Escherichia coli $\mathrm{K}-12$. Science 131 :932-933.

19. LOEB, T., AND N. D. ZINDER. 1961. A bacteriophage containing RNA. Proc. Natl. Acad. Sci. U.S. 47:282-289.

20. LuRIA, S. E. 1945. Mutations of bacterial viruses affecting their host range. Genetics 30:84-99.

21. LURIA, S. E. 1953. Host-induced modifications of viruses. Cold Spring Harbor Symp. Quant. Biol. 18:237-244.

22. Luria, S. E., J. N. Adams, and R. C. Ting. 1960. Transduction of lactose-utilizing ability among strains of $E$. coli and $S$. dysenteriae and the properties of the transducing particles. Virology 12:348-390.

23. MäKelä, P. H., J. Lederberg, AND E. M. LederBERG. 1962. Patterns of sexual recombination in enteric bacteria. Genetics 47:1427-1439.

24. Matsushiro, A. 1963. Specialized transduction of tryptophan markers in E. coli $\mathrm{K}-12$ by bacteriophage $\phi 80$. Virology 19:475-482.

25. Mitsuhashi, S., K. Harada, and M. Kameda. 1961. Elimination of transmissible drug-resistance by treatment with acriflavine. Nature 189: 947.

26. MiYAKE, T. 1962. Exchange of genetic material between Salmonella typhimurium and Escherichia coli K-12. Genetics 47:1043-1052.

27. Miyake, T., AND M. Demerec. 1959. SalmonellaEscherichia hybrids. Nature 183:1586.

28. MorSE, M. L., E. M. LeDERBERG, AND J. LeDERBERG. 1956. Transduction in $E$. coli $\mathrm{K}-12$. Genetics 41 :142-156.

29. ØRSKOV, I., AND F. ØRSKOV. 1960. An antigen termed $\mathrm{f}^{+}$occurring in $\mathrm{F}^{+} E$. coli strains. Acta Pathol. Microbiol. Scand. 48:37-46.

30. Richter, A. 1961. Attachment of wild type F factor to a specific chromosomal region in a variant strain of Escherichia coli K-12: the phenomenon of episomic alternation. Genet. Res. 2:333-345.

31. Swanstrom, M., and M. H. Adams. 1951. Agar layer method for production of high titer phage stocks. Proc. Soc. Exptl. Biol. Med. 78:372375.

32. ZINDER, N. D. 1960. Hybrids of Escherichia and Salmonella. Science 131:813-815.

33. ZINDER, N. D. 1960. Sexuality and mating in Salmonella. Science 131 :924-926. 